The Relationship between Socioeconomic Status, Family Income, and Measures of Muscular and Cardiorespiratory Fitness in Colombian Schoolchildren

Article in Journal of Pediatrics · February 2017

DOI: 10.1016/j.jpeds.2016.12.058

CITATIONS

6

7 authors, including:

Robinson Ramírez-Vélez

Universidad del Rosario 415 PUBLICATIONS $\mathbf{1 , 5 6 0}$ CITATIONS

SEE PROFILE

Daniel Dylan Cohen

University of Santander

60 PUBLICATIONS 813 CITATIONS

SEE PROFILE
READS

124

Felipe Lobelo

Division of Diabetes Translation

112 PUBLICATIONS 5,007 CITATIONS

SEE PROFILE

Gundi Knies

University of Essex

48 PUBLICATIONS 282 CITATIONS

SEE PROFILE

Some of the authors of this publication are also working on these related projects:

Effects of a Single Session of Progressive Resistance Training vs. High-intensity Interval Training on Neurotrophic Factors and Cognitive Performance in Inactive Overweight Individuals (BrainFit Study): A Randomised Controlled Trial View project

Childhood economic circumstances and child well-being View project 


\title{
The Relationship between Socioeconomic Status, Family Income, and Measures of Muscular and Cardiorespiratory Fitness in Colombian Schoolchildren
}

\author{
Gavin R. H. Sandercock, $\mathrm{PhD}^{1, \star}$, Felipe Lobelo, $\mathrm{PhD}^{2}$, Jorge E. Correa-Bautista, PhD³, Gustavo Tovar, $\mathrm{MD}^{3}$, \\ Daniel Dylan Cohen, $\mathrm{PhD}^{4}$, Gundi Knies, $\mathrm{PhD}^{5}$, and Robinson Ramírez-Vélez, $\mathrm{PhD}^{3, \star}$
}

Objective To determine the associations between socioeconomic status (SES) and physical fitness in a sample of Colombian youth.

Study design Prueba SER is cross-sectional survey of schoolchildren in Bogota, Colombia. Mass, stature, muscular fitness (standing long-jump, handgrip), and cardiorespiratory fitness (20-m shuttle run) were measured in 52187 schoolchildren 14-16 years of age. Area-level SES was categorized from 1 (very low) to 4 (high) and parentreported family income was categorized as low, middle, or high.

Results Converting measures into z scores showed stature, muscular, and cardiorespiratory fitness were significantly $(z=0.3-0.7)$ below European values. Children in the mid- and high SES groups jumped significantly further than groups with very low SES. Differences were independent of sex but became nonsignificant when adjusted for anthropometric differences. Participants in the mid-SES and high-SES groups had better handgrip scores when adjusted for body dimension. There were, however, no significant between-group differences in cardiorespiratory fitness, which was strongly clustered by school and significantly greater in students from private schools.

Conclusions Area-level SES is associated with measures of muscular fitness in Colombian schoolchildren. These associations were largely explained by the large differences in body dimensions observed between SES groups. When area-level SES is considered, there was no evidence that family income influenced fitness. The clustering of outcomes reaffirms the potential importance of schools and area-level factors in promoting fitness through opportunities for physical activity. Interventions implemented in schools, can improve academic attainment; a factor likely to be important in promoting the social mobility of children from poorer families. (J Pediatr 2017; $\mathbf{\square}: \mathbf{\square}-\mathbf{\square}$ ).

\section{See editorial, p cos}

he negative gradient between socioeconomic status (SES) and prevalence of noncommunicable disease in adulthood has prompted investigation of potential foundations based in childhood. ${ }^{1}$ Because children rarely present with clinical manifestations of chronic disease, risk factors that track from early life into adulthood are used as surrogate indicators future health status. ${ }^{1,2}$ Excess adiposity and poor physical fitness and low cardiorespiratory or muscular fitness in particular are associated independently with poor cardiometabolic health in children. ${ }^{2}$ Fluctuations in fitness predominantly are the result of changes in habitual physical activity, modulated by genetic and early life (epigenetic) factors.

The relatively poor tracking of physical activity from childhood into adulthood hampers attempts to determine the associations between childhood physical activity and adult health. ${ }^{3}$ Compared with physical activity, physical fitness is a more potent indicator of cardiometabolic health status, ${ }^{2-4}$ which also tracks more strongly from childhood into adulthood.

Children from families with high and middle SES designations tend to perform better on physical fitness tests than those from low SES backgrounds. ${ }^{5-7}$ Reports of the association between SES and fitness appear to vary according to the method of fitness assessment ${ }^{8}$ and the classification of $\mathrm{SES}^{9}$ used. Far less is known of the association between SES and fitness in low- to middle-income countries. ${ }^{10}$ Petroski et $\mathrm{al}^{10}$ found Brazilian children from families of low SES were $40 \%$ less likely to meet criterion-referenced standards for multicomponent fitness. Urban-dwelling youth from Ecuador ${ }^{11}$ and Chile ${ }^{12}$ were found to be fitter than those from rural

$\begin{array}{ll}\text { BMI } & \text { Body mass index } \\ \text { SES } & \text { Socioeconomic status } \\ \text { SISBEN } & \text { System of Identifying Potential Beneficiaries of Social Programs }\end{array}$

From the ${ }^{1}$ Centre for Sports and Exercise Science, School of Biological Sciences, University of Essex, Essex United Kingdom; ${ }^{2}$ Hubert Department of Global Health, Rollins School of Public Health, Emory University, Atlanta, GA; ${ }^{3}$ Center of Studies in Physical Activity

Measurements, School of Medicine and Health Sciences, University of Rosario, Bogotá, District Capital, Colombia; ${ }^{4}$ Faculty of Life Sciences, University of Santander (UDES), Bucaramanga, Colombia; and ${ }^{5}$ Institute for Social \& Economic Research, University of Essex, Essex, United Kingdom

${ }^{*}$ Contributed equally.

Supported by Secretary of Education District of BogotáSED (300-2014) and University of Rosario (671-2014) The content of this report reflects the authors' views alone, and the Colombian Community or the Universidad del Rosario is not liable for any use that may be made of the information contained herein. The authors declare no conflicts of interest.

0022-3476/\$ - see front matter. @ 2016 Elsevier Inc. All rights reserved.

http://dx.doi.org10.1016/.jpeds.2016.12.058 
areas. Because there are greater concentrations of higher SES neighborhoods within urban areas in both countries, these data also suggest a positive association between SES and physical fitness. In contrast, a recent report on Colombian children and adolescents found that greater SES was associated with a lower handgrip strength. ${ }^{13}$

Much of Latin America is undergoing a change in nutritional habits with associated reductions in population-level physical activity ${ }^{13}$ In high-income countries, low SES is a recognized risk factor for childhood and adult obesity. In transitional countries, residents of high SES neighborhoods commonly adopt "Westernized lifestyles," ${ }^{11,12}$ which can have negative as well as positive impacts on health through changes in physical activity, body composition, and fitness.

The primary aim of this study was, therefore, to determine whether physical fitness is associated with SES in a large sample of schoolchildren from the district of Bogota, Colombia, a rapidly developing high-middle income country, and whether any associations were independent of any differences in body size identified between SES groups. Second, we aimed to determine whether fitness was associated with family income and other sociogeographic factors and whether associations were independent of SES and differences in body size.

\section{Methods}

This was a cross-sectional survey of ninth grade students participating in the 2015 " $40 \times 40$ Curriculum" and Prueba SER Survey, ${ }^{14}$ administered by the District Secretary of Education in November 2015. Participants were recruited from public and private schools in all 20 "localidades" (municipalities) within the District Capital of Bogota (Cundinamarca Department, Andean Region of Colombia). This is a predominantly urban area with 7862277 inhabitants ${ }^{4}$ between 2500 and $3250 \mathrm{~m}$ above sea level. The Review Committee for Research Human Subjects at the University of Rosario (Code no. CEI-ABN026000262) approved the study. The nature and purpose of the study were communicated to potential participants and their parents or guardians, with the explanation that data would be available to the Colombian Health Authorities in accordance with the Law of Data Protection (Resolution 8430/93).

Data were collected in schools by 20 teams of trained researchers $(\mathrm{n}=6$ per team). Before data collection, researchers completed 6 theoretical and practical training sessions to standardize the assessment process and to minimize interobserver variability.

\section{Anthropometric Measurements}

All assessments were performed between 7:00 a.m. and 10:00 a.m., following an overnight fast. During all anthropometric measurements, students wore light clothing and were barefoot. During body mass measurements, the student stood on the scale for 5 seconds with feet hip-width apart. Mass was measured to the nearest $0.1 \mathrm{~kg}$. During standing height (stature) measurement, the student stood with heels together and heels touching the base of the stadiometer and head positioned in the Frankfort plane with eyes looking straight ahead. Stature was measured to the nearest $0.1 \mathrm{~cm}$. Decimal age was calculated by subtraction of participants' date of birth from the LMSgrowth macro (Harlow Healthcare, Tyne \& Wear, United Kingdom), ${ }^{15}$ and body mass, stature, and body mass index (BMI) were expressed as z scores based on global reference date. ${ }^{16} \mathrm{BMI}$ was classified as underweight, normal weight, overweight, or obese by use of the criteria of the International Obesity Task Force. ${ }^{17}$

\section{Physical Fitness}

The test protocols used are appropriate for use in this age group in and have acceptable levels of validity ${ }^{8}$ and reliability. ${ }^{9}$ We used standing long-jump (Jump) to assess lower body muscular fitness. Students were instructed to jump as far as possible using a 2 -footed takeoff and landing technique. They were encouraged to flex then extend their knees, ankles, and hips and to swing their arms to maximize performance. Jump performance was calculated as the distance between the toes at takeoff to the heels at the landing point. The best score from 2 correctly performed jumps was used.

We used isometric handgrip dynamometry (Handgrip) as an indicator of upper-body muscular fitness with an adjustable analog handgrip dynamometer T-18 TKK SMEDLY III (Takei Scientific Instruments Co, Ltd, Niigata, Japan). Students watched a brief demonstration of technique and were given verbal instructions on how to perform the test. If necessary, the dynamometer was adjusted according to the child's hand size according to predetermined protocols. Monthly, each dynamometer was tested via a standardized calibration procedure that showed that the device was within $1 \mathrm{~kg}$ of accuracy over the whole measuring range (from 0 to $100 \mathrm{~kg}$ ), and with a 100 -g sensitivity.

Cardiorespiratory fitness was assessed with the 20 -m shuttlerun test as described by Ortega et al. ${ }^{2}$ Participants ran between 2 lines $20 \mathrm{~m}$ apart in time with prerecorded signals. The initial speed of $8.5 \mathrm{~km} \cdot \mathrm{h}^{-1}$ increased by $0.5 \mathrm{~km} \cdot \mathrm{h}^{-1}$ each minute, and the test was terminated when participants failed to reach the end lines (keep pace) on 2 consecutive occasions or when the subject stopped due to volitional fatigue. The protocol tends to elicit a maximal response in children and adolescents, irrespective of which criterion results in termination of the test. ${ }^{2}$ Performance was reported as running speed $\left(\mathrm{km} \cdot \mathrm{h}^{-1}\right)$ at the final completed stage. Valid cases were those with valid data for Jump, Handgrip, and accompanying anthropometric and demographic information.

We removed 83 participants because of missing age data or invalid birth date. A further 168 cases were removed because of missing data for either mass or stature; 437 cases because of missing Handgrip; and 1758 because of missing or invalid Jump data. We rejected a further 1265 cases identified as duplicates (identical school roll number and name). The final sample with complete anthropometric and muscular fitness analysis comprised 52204 participants age $15( \pm 1)$ years, of whom $51 \%(n=26630)$ were male. These data were expressed as continuous $\mathrm{z}$ scores based on a combination reference data ${ }^{18-20}$ to provide reference values for the entire age range. There are no agreed-on criterion references standards 
for muscular fitness. Complete shuttle-run data were available for $66 \%(n=34616)$ of participants but missing data were nonrandom. Data were more likely to be missing for children living in very low SES areas.

\section{Socioeconomic Status}

SES was determined by the System of Identifying Potential Beneficiaries of Social Programs (SISBEN for its Spanish initials, 1-6 on a scale defined by the Colombian authorities). It takes into account sociodemographic characteristics (family composition, employment status, family income, and educational level), living conditions (construction type and materials), and access to public utilities (sewer, electricity, potable water, and garbage collection). Households with SISBEN-low low, 2-low, and 3-medium low are the most vulnerable and targeted in social programs. SISBEN level 4-medium, 5-medium high, and 6-high strata are considered the least vulnerable sectors of society. SISBEN 4-6 are regarded as wealthy, and we collapsed these to form a single category (high SES). For clarity, we also renamed strata 3 as "mid SES" and 1 as "very low SES." We therefore categorize SES as very low; second, we obtained parental income data to calculate family income, which was classified as 1 (low), 2 (mid), and 3 (high).

\section{Statistical Analyses}

ANCOVA adjusted for sex was used to determine main effects for SES (very low, low, mid, high), family income between, and sex. We calculated main effects for fixed factors (SES, family income) and the SES $\times$ family income interaction. We calculated mixed regression modeling for the school-level clustering of each outcome (Model ${ }_{0}$ ). In Model $_{1}$ we calculated sexadjusted estimates for SES (referent: very low). In $\mathrm{Model}_{2}$ we adjusted for public or private education and rural vs urban dwelling) and for family income (referent: low income, Model $_{3}$ ). Finally, estimates for Jump and Handgrip were adjusted for stature $\left(\mathrm{Model}_{4}\right)$.

\section{Results}

Table I shows anthropometric values based on global reference data. Mean values for body mass were close to reference values in both sexes, but stature was below expected in boys $(z=-0.42)$ and in girls $(z=-0.76)$. Girls were more likely be overweight or obese than boys, but fewer were underweight. In total, $6.9 \%$ of boys were underweight with $0.9 \%$ severely underweight. Table I shows the sociogeographic data by sex.

\section{Differences in Anthropometric Values by SES and Family Income}

Tables II and III (available at www.jpeds.com) provide the unadjusted means for anthropometric measures ( $\mathrm{z}$ scores) and the results of sex-adjusted analysis of mean differences (ANCOVA). Significant main effects of SES for mass and stature indicated greater stature and body mass in greater SES groups but few differences according to family income. All physical fitness values were below European reference values (Table I).
Greater SES was associated with better Jump (Table II). Participants in the mid-SES group had the greatest mean for cardiorespiratory fitness.

\section{Multilevel Regression Analysis}

Tables IV-VI show the regression models for each fitness measure. The significant, independent contribution of schooland locality-level clustering is shown in Model $_{0}$ for each outcome. Clustering of values by school was significant and was greater than by locality for all measures.

Mid- and high-SES groups had significantly better Jump than very low-SES groups independent of sex $\left(\operatorname{Model}_{2}\right)$. Model 3 also shows the independence of rural vs urban dwelling and family income. Adjusting for differences in stature $\left(\mathrm{Model}_{4}\right)$ meant the Jump performance no longer differed significantly between mid- and very low SES. It also reversed in direction the association between Jump and high SES $(\beta=-0.134, P<.05)$ and a negative association between Jump and rural-dwelling participants $(\beta=-0.146, P<.05)$.

SES did not predict Handgrip z scores in Models I-3 $_{1-3}$. Female sex and rural dwelling were associated with lower Handgrip $\left(\mathrm{Model}_{3}\right)$ and remained so in $\mathrm{Model}_{4}$. When we corrected for stature $(\beta=0.199, P<.0001)$ Handgrip was significantly greater in children the mid-SES $(\beta=0.079, P<.05)$ and high-SES $(\beta=0.239, P<.0001)$ groups compared with children in the low-SES group.

Cardiorespiratory fitness data were only available in 34616 participants and were clustered heavily by school. Linear regression could identify no significant associations between anthropometric variables and shuttle z score, so only Models 1-3 were created. There were no differences in shuttle $\mathrm{z}$ score between SES groups. Attending private school was the only significant predictor of (greater) sex-adjusted cardiorespiratory fitness $(\beta=0.163 P<.05)$.

\section{Discussion}

Our findings support those of previous studies highlighting socioeconomic inequalities in the physical fitness of youth. , $^{1,7,21-23}$ The few studies that have attempted to determine how SES interacts with other sociogeographical factors associated with fitness have produced somewhat-contradictory findings. ${ }^{1,5,7,13}$ The present results also agree with previous evidence ${ }^{5}$ suggesting that SES-related differences in body size can explain at least partly the association between SES and physical fitness.

In high-income countries, physical fitness and SES are 2 determinants of health which, in high-income counties, also are correlated positively with one another. ${ }^{4-6}$ The scarce data available from low- to middle-income countries are more heterogeneous, with evidence suggesting that youth from either families mid- ${ }^{8}$ or high SES ${ }^{9,10}$ groups have greater cardiorespiratory fitness and muscle strength than low-SES groups, or that muscle strength is greater in youth of lower SES. ${ }^{13}$ We aimed to disentangle the complex web of geographic and anthropometric factors that may interact with SES as a determinant of health-related fitness in children from the fastestgrowing city in Colombia. 


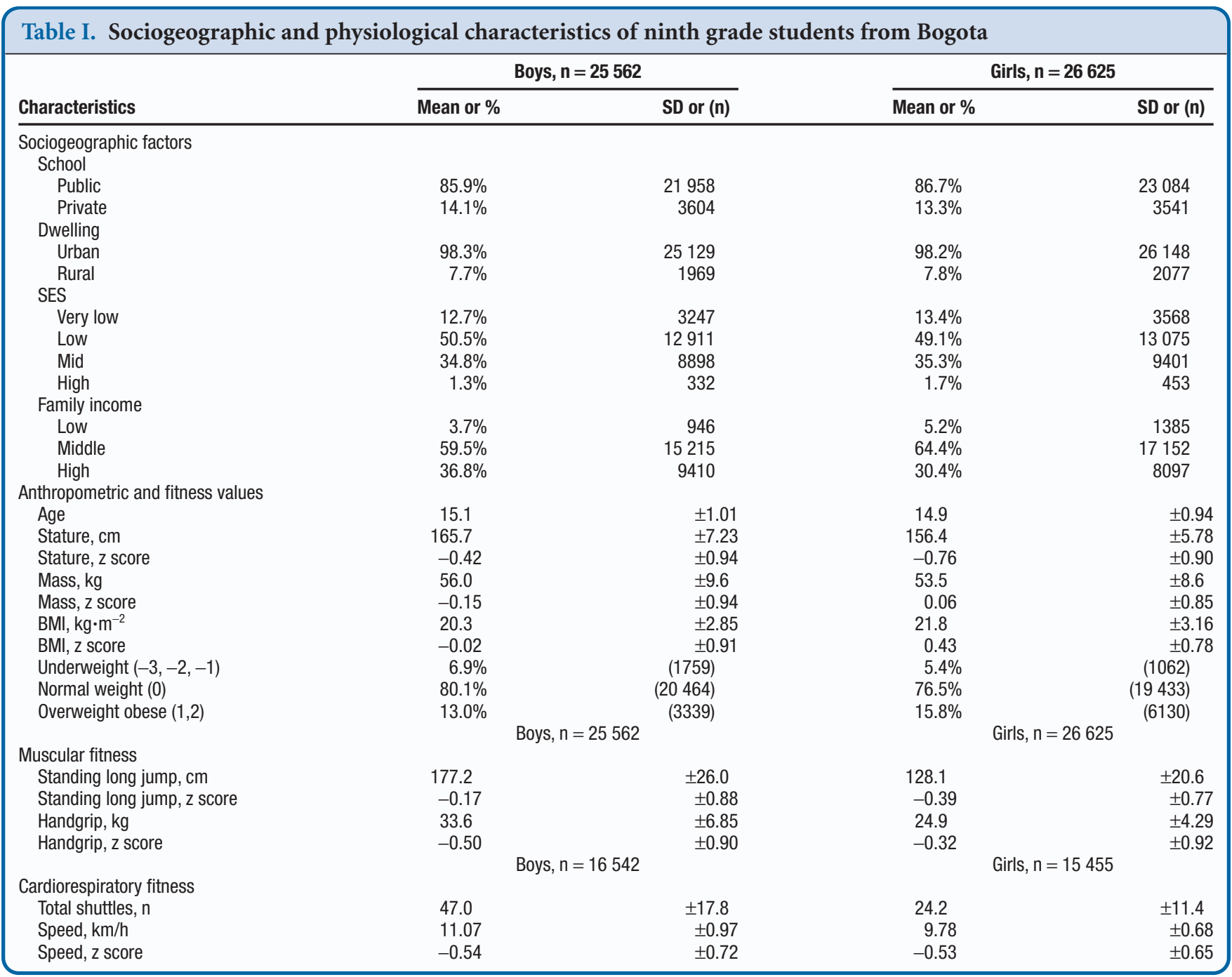

BMI z scores calculated via use of the World Health Organization/Centers for Disease Control and Prevention reference values; underweight, normal weight overweight, and obese were classified with the International Obesity Task Force Criteria. Horizontal Jump: best from 2 attempts.

Stature and mass also are determinants of fitness test performance, including Handgrip and Jump and to a lesser extent cardiorespiratory fitness. ${ }^{24,25}$ Freitas et $\mathrm{al}^{7}$ reported better Jump performance in girls in the high vs low SES groups but no differences in boys. Using a multifactorial index of SES, Jiminez Pavon et $\mathrm{al}^{5}$ found that Jump distance increased across children in the low, moderate, and high SES groups, after adjusting for age, height, and adiposity but not sociogeographic factors or potential clustering.

In our multilevel analysis, mid- or high SES was associated with significantly better Jump performance after we adjusted for sex and clustering at the level of locality and school; however, further adjustment $\left(\mathrm{Model}_{4}\right)$ to remove the influence of stature changed the association between SES and Jump dramatically. Mid-SES was no longer associated with Jump, and high SES was negatively associated with Jump. Accounting for differences in stature meant private education and female sex were both associated with better Jump and rural dwelling was associated with lower performance. This finding suggests that the unadjusted values showing better Jump in children in the
mid-SES and high-SES groups largely are due to their greater stature.

Low handgrip strength is associated with a greater metabolic risk score in adolescents, ${ }^{2,26}$ and poorer handgrip strength is reported in lower SES groups of Spanish ${ }^{5,27}$ and Brazilian ${ }^{10}$ descent. In Bogotá, we found that handgrip was greater in youth in the mid- and high-SES groups when estimates were adjusted fully. Our findings are in contrast with those of Otero et $\mathrm{al},{ }^{13}$ who reported that greater SES was associated with lower handgrip in a sample that included both rural and urban Colombian youth. No previous studies, however, have corrected for school-level clustering ${ }^{6,7}$ or public/private educational status, both of which made important contributions to our fully adjusted model.

Previous investigations of the association between SES and cardiorespiratory fitness have provided more mixed results. The Pan-European HELENA (Healthy Lifestyle in Europe by $\mathrm{Nu}-$ trition in Adolescence $)^{5}$ study showed greater cardiorespiratory fitness in children in the greater SES group in both sexes, and more modest differences were reported in the Spanish 


\begin{tabular}{|c|c|c|c|c|c|}
\hline Characteristics & Model $_{0}$ & Model $_{1}$ & $\mathrm{Model}_{2}$ & $\mathrm{Model}_{3}$ & Model $_{4}$ \\
\hline SES & & $\beta$ & $\beta$ & $\beta$ & $\beta$ \\
\hline Very low SES & & - & - & - & - \\
\hline LoW SES & & 0.023 & 0.030 & 0.024 & -0.027 \\
\hline Mid SES & & $0.099^{*}$ & $0.096^{\star}$ & $0.101^{*}$ & -0.038 \\
\hline High SES & & $0.281^{\dagger}$ & $0.252^{\dagger}$ & $0.285^{\dagger}$ & $-0.134^{\star}$ \\
\hline Sex (female) & & $-0.221^{\dagger}$ & $-0.223^{\dagger}$ & $-0.222^{\dagger}$ & $0.335^{\dagger}$ \\
\hline School (private) & & & -0.068 & -0.068 & $0.165^{\ddagger}$ \\
\hline Dwelling (rural) & & & -0.053 & -0.055 & $-0.146^{\dagger}$ \\
\hline \multicolumn{6}{|l|}{ Family income } \\
\hline Family income low & & & & - & - \\
\hline Family income mid & & & & 0.012 & -0.016 \\
\hline Family income high & & & & 0.026 & -0.011 \\
\hline Stature (z score) & & & & & $0.458^{\dagger}$ \\
\hline $\begin{array}{l}\text { Constant } \\
\text { Random factors }\end{array}$ & $-0.241^{\dagger}$ & $-0.286^{\dagger}$ & $-0.233^{\dagger}$ & $-0.220^{\dagger}$ & $-0.235^{\dagger}$ \\
\hline School & $-10.8^{\dagger}$ & $-3.09^{*}$ & $-4.36^{\ddagger}$ & $-4.11^{*}$ & $-4.10^{\star}$ \\
\hline Locality & $-1.75^{\dagger}$ & $-1.31^{\dagger}$ & $-1.33^{\dagger}$ & $-1.32^{\dagger}$ & $-1.33^{\dagger}$ \\
\hline Residuals (In) & $-0.233^{\dagger}$ & $-0.229^{\dagger}$ & $-0.239^{\dagger}$ & $-0.239^{\dagger}$ & $-0.239^{\dagger}$ \\
\hline
\end{tabular}

Values corrected for clustering by school $(n=489)$ with average cluster size $n=68$ participants and locality $(n=20)$ with average cluster size $n=1600$ participants. SES categories very low $=$ national SES stratum 1, low $=2$, mid $=3$; high, comprises Columbian national SES strata 4-6. Model 4 : stature identified as potential anthropometric confounder based on a priori linear regression.

${ }^{*}$ Significant at $P<.05$.

†Significant at $P<.001$

¥Significant at $P<.01$.

AVENA (Feeding and Assessment of Nutritional Status of Spanish Adolescents) study, and differences were observed only in girls and then only according to parental profession but not level of education. We found that even though cardiorespiratory fitness differed little according to SES, values were clus-

Table V. Mixed linear regression model for upper body muscular fitness (handgrip dynamometry, $z$ score) in 52187 Colombian schoolchildren aged 14-16 years

\begin{tabular}{lccccc}
\hline Characteristics & Model $_{\mathbf{0}}$ & Model $_{1}$ & Model $_{2}$ & Model $_{3}$ & Model $_{4}$ \\
\hline SES & & $\beta$ & $\beta$ & $\beta$ & $\beta$ \\
Very low SES & & $\dagger$ & - & - & - \\
Low SES & & -0.002 & -0.015 & -0.001 & 0.017 \\
Mid SES & & 0.018 & -0.017 & 0.020 & $0.080^{\star}$ \\
High SES & -0.026 & -0.107 & -0.020 & $0.240^{\dagger}$ \\
Sex (female) & $-0.180^{\dagger}$ & $-0.178^{\dagger}$ & $-0.17^{\dagger}$ & $-0.153^{\dagger}$ \\
School type (private) & & & 0.120 & 0.120 & -0.043 \\
Urban/rural (rural) & & & $-0.085^{\ddagger}$ & $-0.087^{\dagger}$ & $-0.081^{\star}$ \\
Family income (low) & & & & - & - \\
Family income (mid) & & & & -0.014 & 0.011 \\
Family income (high) & & & & 0.009 & 0.018 \\
Stature (z score) & & & & & $0.199^{\dagger}$ \\
Constant & $-0.131^{\dagger}$ & $-0.415^{\dagger}$ & $-0.490^{\dagger}$ & $-0.498^{\dagger}$ & $-0.491^{\dagger}$ \\
Random factors & & & & & \\
School & $-9.980^{\dagger}$ & $-4.138^{\dagger}$ & $-3.863^{\dagger}$ & $-3.781^{\dagger}$ & $-3.768^{\dagger}$ \\
Locality & $-1.340^{\dagger}$ & $-1.651^{\dagger}$ & $-1.665^{\dagger}$ & $-1.683^{\dagger}$ & $-1.685^{\dagger}$ \\
Residuals (In) & $-0.266^{\dagger}$ & $-0.107^{\dagger}$ & $-0.112^{\dagger}$ & $-0.112^{\dagger}$ & $-0.112^{\dagger}$ \\
\hline
\end{tabular}

Values corrected for clustering by school $(n=489)$ with average cluster size $n=68$ participants and locality $(n=20)$ with average cluster size $n=1600$ participants. SES categories very low 1, low 2, mid, high comprises SES classifications 4 and 5. Model 4 : stature identified as potential anthropometric confounder based on a priori linear regression.

*Significant at $P<.05$.

tSignificant at $P<.001$

¥Significant at $P<.01$.
Table VI. Mixed linear regression model fitting for cardiorespiratory fitness (20-m shuttle run, $\mathrm{z}$ score) in 34616 Colombian schoolchildren aged 11-18 years

\begin{tabular}{lccccc}
\hline Characteristics & Model $_{\mathbf{0}}$ & Model $_{\mathbf{1}}$ & Model $_{\mathbf{2}}$ & Model $_{\mathbf{3}}$ & Model $_{\mathbf{4}}$ \\
\hline SES & & $\beta$ & $\beta$ & $\beta$ & $\beta$ \\
Very low SES & & - & - & - & - \\
Low SES & & -0.043 & -0.057 & -0.043 & - \\
Mid SES & 0.007 & 0.005 & 0.007 & - \\
High SES & -0.037 & -0.007 & -0.038 & - \\
Sex (female) & $-0.026^{*}$ & $-0.026^{\star}$ & $-0.026^{*}$ & - \\
School type (private) & & & $0.163^{\dagger}$ & $0.163^{\dagger}$ & - \\
Urban/rural (rural) & & & 0.056 & 0.056 & - \\
Family income (low) & & & - & - & \\
Family income (mid) & & & & 0.004 & - \\
Family income (high) & & & & 0.002 & - \\
Constant & -0.546 & -0.509 & -0.530 & -0.533 & - \\
Random factors & & & & & \\
School ( $\mathrm{n}=489$ ) & $-11.84^{\dagger}$ & $-11.39^{\dagger}$ & $-13.10^{\ddagger}$ & $-12.98^{\ddagger}$ & - \\
Locality (n=20) & $-1.591^{*}$ & $-1.599^{*}$ & -1.612 & -1.612 & - \\
Residuals (In) & $-0.420^{*}$ & $-0.420^{\star}$ & -0.042 & -0.420 & - \\
\hline
\end{tabular}

Values are corrected for clustering by schools ( $n=381$ ); average cluster size $n=74$ participants and by locality $(n=20)$; average cluster size $n=1450$ participants. SES categories: very low $=1$, low $=2$, mid $=3$, high $=4-5$ High comprises SES classifications 4 and 5. Model ${ }_{4}$ was not calculated because no anthropometric confounders were identified.

* Significant at $P<.05$.

†Significant at $P<.001$.

‡Significant at $P<.01$.

tered strongly by school, with greater fitness observed in privately educated youth. Again, these factors have not been considered specifically in previous studies of the association between SES and fitness. ${ }^{5,7,27}$ Greater cardiorespiratory fitness in private schools may be attributable to superior facilities and students' greater rates of participation in sports and activities, which promote cardiorespiratory fitness, during and after school. Colombian public schools are mandated to provide 2 hours of weekly physical education compared with the 4-6 hours typical of private schools. The present findings should, however, be interpreted with some caution, because we cannot rule out sample bias as an explanation (Tables II and III).

Although we did not observe a clear, direct association between SES and physical fitness in children from Bogotá, as has been shown to some extent, elsewhere, ${ }^{5,7,27}$ the present data do suggest that area-level SES may influence fitness to a greater extent than family income. This may be because this is a better indicator of local-area amenities that provide children with the opportunity to develop or maintain fitness via access to safe play areas or sporting infrastructure. ${ }^{28}$

Adjusting (already age- and sex-normalized) estimates of fitness for anthropometric differences had strong effects on the relationship between fitness and SES. The significant contribution of anthropometric differences to SES-related variations in fitness is clearly important and should be explored further and adjusted for, where necessary, in future research. Lower birth weight, which is associated with poorer childhood muscular fitness, also is more common in children from families of lower SES and might contribute to poorer unadjusted Handgrip and Jump performance. Gestation at an altitude such as that of Bogotá is associated with lower birth weight, ${ }^{29}$ which may partly explain the substantially lower 
handgrip values in the present study compared with European data ${ }^{30}$ for children of the same age.

A strength of this study is the sample size, but the underrepresentation of very low and very high (Level 6) individuals means the present data provide an accurate description of the associations between fitness and SES only across the low-to-middle class strata of Colombian society. Although these strata account for the majority of the population, the need to collapse SES strata for analyses may have reduced the fidelity of stratification. Further research may need to use booster samples identified as harder to reach to better characterize the relationship across all SES groups. Similar studies show evidence of nonrandom missing data for the 20-m shuttle-run test within multicomponent fitness assessments, ${ }^{7}$ but this study identified and characterized missing cardiorespiratory fitness data. Missing data resulted in an underrepresentation of children in the very low SES group. Data often were missing at school-level, possibly because schools in the most deprived areas lacked the space or facilities needed to perform the $20-\mathrm{m}$ shuttle-run test.

Our study suggests that area-level SES is associated with muscular fitness in ninth grade students from Bogota, but this association is influenced by SES-related variation in anthropometric measures. After we considered area-level SES, fitness was not associated independently with family income. Improving area-level factors associated with children's participation in physical activity and in turn development of fitness is a more viable and cost-effective prospect than increasing the income of their families. ${ }^{21,24}$ Both locality and schools accounted for a large proportion of the observed variance in muscular and cardiorespiratory fitness, suggesting these have potentially important roles as moderators of children's fitness, at least in the urban environment of a rapidly developing middle-income country. ${ }^{31}$

We thank the Bogota District Education Department for supporting data collection for this study, as well as the participating Bogota District students, teachers, schools, and staff.

Submitted for publication Jul 14, 2016; last revision received Dec 5, 2016; accepted Dec 19, 2016

Reprint requests: Robinson Ramírez-Vélez, PhD, University of Rosario, Bogotá, DC, Colombia. E-mail: robin640@ hotmail.com; robinson.ramirez@urosario.edu.co

\section{References}

1. van de Mheen H, Stronks K, Looman CWN, Mackenbach JP. Does child hood socioeconomic status influence adult health through behavioural factors? Int J Epidemiol 1998;27:431-7.

2. Ortega FB, Ruiz JR, Castillo MJ, Sjöström M. Physical fitness in childhood and adolescence: a powerful marker of health. Int J Obes (Lond) 2008;32:1-11.

3. Cleland V, Dwyer T, Venn A. Which domains of childhood physical activity predict physical activity in adulthood? A 20 -year prospective tracking study. Br J Sports Med 2012;46:595-602.

4. Gualteros JA, Torres JA, Umbarila-Espinosa LM, Rodríguez-Valero FJ, Ramírez-Vélez R. A lower cardiorespiratory fitness is associated to an unhealthy status among children and adolescents from Bogota, Colombia. Endocrinol Nutr 2015;62:437-46.
5. Jimenez Pavon D, Ortega FP, Ruiz JR, España Romero V, García Artero E, Moliner Urdiales D, et al. Socioeconomic status influences physical fitness in European adolescents independently of body fat and physical activity: the HELENA study. Nutr Hosp 2010;25:311-6.

6. Jin Y, Jones-Smith JC. Associations between family income and children's physical fitness and obesity in California, 2010-2012. Prev Chronic Dis 2015;12:E17.

7. Freitas D, Maia J, Beunen G, Claessens A, Thomis M, Marques A, et al. Socio-economic status, growth, physical activity and fitness: the Madeira Growth Study. Ann Hum Biol 2007;34:107-22.

8. Ruiz JR, Castro-Pinero J, Espana-Romero V, Artero EG, Ortega FB, Cuenca MM, et al. Field-based fitness assessment in young people: the ALPHA health-related fitness test battery for children and adolescents. Br J Sports Med 2011;45:518-24

9. Ramirez-Velez R, Rodrigues-Bezerra D, Correa-Bautista JE, Izquierdo M. Reliability of health-related physical fitness tests among Colombian children and adolescents: the FUPRECOL study. PLoS ONE 2015;10:e0140875.

10. Petroski EL, da Silva AF, Rodrigues AB, Pelegrini A. Health-related physical fitness in Brazilian adolescents from areas having a medium/low Human Development Index. Rev Salud Publica (Bogota) 2011;13:219-28.

11. Andrade S, Ochoa-Aviles A, Lachat C, Escobar P, Verstraeten R, Van Camp J, et al. Physical fitness among urban and rural Ecuadorian adolescents and its association with blood lipids: a cross sectional study. BMC Pediatr 2014;14:106.

12. Garber MD, Sajuria M, Lobelo F. Geographical variation in healthrelated physical fitness and body composition among Chilean 8th graders: a nationally representative cross-sectional study. PLoS ONE 2014;9:e108053.

13. Otero J, Cohen DD, Herrera VM, Camacho PA, Bernal O, LópezJaramillo P. Sociodemographic factors related to handgrip strength in children and adolescents in a middle income country: the SALUS study. Am J Hum Biol 2016;doi:10.1002/ajhb.22896. Epub ahead of print.

14. Secretaria de Educación. Plan de desarrollo Bogotá humana 2012-2016. Bogota DC, Colombia: Secretaria de Gobierno, Bogota DC, Colombia; 2012.

15. Cole TJ. The LMS method for constructing normalized growth standards. Eur J Clin Nutr 1990;44:45-60.

16. Van den Broeck J, Willie D, Younger N. The World Health Organization child growth standards: expected implications for clinical and epidemiological research. Eur J Pediatr 2009;168:247-51.

17. Cole TJ, Bellizzi MC, Flegal KM, Dietz WH. Establishing a standard definition for child overweight and obesity worldwide: international survey. BMJ 2000;320:1240-3.

18. Parizkova J. Impact of education on food behaviour, body composition and physical fitness in children. Br J Nutr 2008;99:S26-32.

19. Baca M, Molak M, Sobczyk M, Węgleński P, Stankovic A. Locals, resettlers, and pilgrims: a genetic portrait of three pre-Columbian Andean populations. Am J Phys Anthropol 2014;154:402-12.

20. Do DP, Frank R, Finch BK. Does SES explain more of the black/white health gap than we thought? Revisiting our approach toward understanding racial disparities in health. Soc Sci Med 2012;74:1385-93.

21. Mutunga M, Gallagher AM, Boreham C, Watkins DC, Murray LJ, Cran $\mathrm{G}$, et al. Socioeconomic differences in risk factors for obesity in adolescents in Northern Ireland. Int J Pediatr Obes 2006;1:114-9.

22. Esmaeilzadeh S, Kalantari H, Nakhostin-Roohi B. Cardiorespiratory fitness, activity level, health-related anthropometric variables, sedentary behaviour and socioeconomic status in a sample of Iranian 7-11 year old boys. Biol Sport 2013;30:67-71

23. Bohr AD, Brown DD, Laurson KR, Smith PJ, Bass RW. Relationship between socioeconomic status and physical fitness in junior high school students. J Sch Health 2013;83:542-7.

24. Gordon-Larsen P, Nelson MC, Page P, Popkin BM. Inequality in the built environment underlies key health disparities in physical activity and obesity. Pediatrics 2006;117:417-24.

25. Bellisle F. Introduction: acquisition of food-related behaviours in children: critical windows for later health. An international pre-FENS congress symposium, Paris July 9, 2007. Br J Nutr 2008;99(suppl 1):S1.

26. Rodríguez Valero FJ, Gualteros JA, Torres JA, Umbarila Espinosa LM, Ramírez-Velez R. Association between muscular fitness and physical health 
status among children and adolescents from Bogotá, Colombia. Nutr Hosp 2015;32:1559-66.

27. Jimenez-Pavon D, Ortega FB, Ruiz JR, Chillón P, Castillo R, Artero EG, et al. Influence of socioeconomic factors on fitness and fatness in Spanish adolescents: the AVENA study. Int J Pediatr Obes 2010;5:467-73.

28. Kwak L, Kremers SP, Bergman P, Ruiz JR, Rizzo NS, Sjöström M. Associations between physical activity, fitness, and academic achievement. J Pediatr 2009;155:914-8, e1.
29. Wehby GL, Castilla EE, Lopez-Camelo J. The impact of altitude on infant health in South America. Econ Hum Biol 2010;8:197-211.

30. Ortega FB, Artero EG, Ruiz JR, España-Romero V, Jiménez-Pavón D, Vicente-Rodriguez G, Moreno LA, et al. Physical fitness levels among European adolescents: the HELENA study. Br J Sports Med 2011;45:20-9.

31. Ramírez-Vélez R, Tordecilla-Sanders A, Correa-Bautista JE, Peterson MD, Garcia-Hermoso A. Handgrip strength and ideal cardiovascular health among Colombian children and adolescents. J Pediatr 2016;179:82-9, e1. 


\begin{tabular}{|c|c|c|c|c|c|c|c|c|}
\hline Family incomes & Very low SES & Low SES & Mid SES & High SES & All SES & SES & Family income & Interaction \\
\hline \multicolumn{9}{|l|}{ Mass } \\
\hline Low & $\begin{array}{l}-0.099 \\
\pm 0.916\end{array}$ & $\begin{array}{l}-0.037 \\
\pm 0.907\end{array}$ & $\begin{array}{l}-0.021 \\
\pm 0.902\end{array}$ & $\begin{array}{r}0.262 \\
\pm 0.700\end{array}$ & $\begin{array}{l}-0.038 \\
\pm 0.862\end{array}$ & $\begin{array}{l}F=50.3 \\
P<.001\end{array}$ & $\begin{array}{l}F=30.1 \\
P<.001\end{array}$ & \\
\hline Mid & $\begin{array}{l}-0.103 \\
\pm 0.929\end{array}$ & $\begin{array}{l}-0.089^{\star} \\
\pm 0.907\end{array}$ & $\begin{array}{l}-0.009 \\
\pm 0.879\end{array}$ & $\begin{array}{r}0.109 \\
\pm 0.805\end{array}$ & $\begin{array}{l}-0.062 \\
\pm 0.877\end{array}$ & $\eta_{p}^{2}=0.004$ & $\eta_{p}^{2}=0.002$ & \\
\hline High & $\begin{array}{l}-0.081 \\
\pm 0.893\end{array}$ & $\begin{array}{l}-0.046 \\
\pm 0.909\end{array}$ & $\begin{array}{r}0.044 \\
\pm 0.888\end{array}$ & $\begin{array}{r}0.117 \\
\pm 0.849\end{array}$ & $\begin{array}{l}-0.001 \\
\pm 0.877\end{array}$ & & & \\
\hline All family incomes & $\begin{array}{l}-0.096 \\
\pm 0.909\end{array}$ & $\begin{array}{l}-0.074 \\
\pm 0.908\end{array}$ & $\begin{array}{r}0.010 \\
\pm 0.884\end{array}$ & $\begin{array}{r}0.116 \\
\pm 0.834\end{array}$ & $\begin{array}{l}-0.043 \\
\pm 0.877\end{array}$ & $\begin{array}{l}F=0.42 \\
P=.421\end{array}$ & $\begin{array}{l}F=26.6 \\
P<.001 \\
\eta_{p}=\mathbf{0 . 0 0 0 2}\end{array}$ & $\begin{array}{l}F=0.17 \\
P=.416\end{array}$ \\
\hline \multicolumn{9}{|l|}{ Stature } \\
\hline Low & $\begin{array}{l}-0.831 \\
\pm 0.968\end{array}$ & $\begin{array}{l}-0.060^{\star} \\
\pm 0.961\end{array}$ & $\begin{array}{l}-0.579^{\dagger} \\
\pm 1.13\end{array}$ & $\begin{array}{l}-0.326^{\dagger} \\
\pm 0.961\end{array}$ & $\begin{array}{l}-0.668 \\
\pm 0.905\end{array}$ & $\begin{array}{l}F=128, \\
P<.001\end{array}$ & $\begin{array}{l}F=34.1 \\
P<.001\end{array}$ & \\
\hline Mid & $\begin{array}{l}-0.741 \\
\pm 0.932\end{array}$ & $\begin{array}{l}-0.642 \\
\pm 0.923\end{array}$ & $\begin{array}{l}-0.554^{\dagger} \\
\pm 0.945\end{array}$ & $\begin{array}{l}-0.428^{\dagger} \\
\pm 0.931\end{array}$ & $\begin{array}{l}-0.624 \\
\pm 0.901\end{array}$ & $\eta_{p}^{2}=0.024$ & $\eta_{p}^{2}=0.002$ & \\
\hline High & $\begin{array}{l}-0.692 \\
\pm 0.939\end{array}$ & $\begin{array}{l}-0.569 \\
\pm 0.924\end{array}$ & $\begin{array}{l}-0.465 \\
\pm 0.960\end{array}$ & $\begin{array}{l}-0.279^{\dagger} \\
\pm 0.935\end{array}$ & $\begin{array}{l}-0.530 \\
\pm 0.898\end{array}$ & & & \\
\hline All family incomes & $\begin{array}{l}-0.731 \\
\pm 0.936\end{array}$ & $\begin{array}{l}-0.622 \\
\pm 0.926\end{array}$ & $\begin{array}{l}-0.522 \\
\pm 0.958\end{array}$ & $\begin{array}{l}-0.326^{\dagger} \\
\pm 0.935\end{array}$ & $\begin{array}{l}-0.594 \\
\pm 0.901\end{array}$ & $\begin{array}{l}F=34.6 \\
P<.001 \\
\eta_{p}{ }^{2}=\mathbf{0 . 0 0 2}\end{array}$ & $\begin{array}{l}F=5.38 \\
P=.005 \\
\boldsymbol{\eta}_{p}{ }^{2}=\mathbf{0 . 0 0 0 1}\end{array}$ & $\begin{array}{l}F=0.688 \\
P=.659\end{array}$ \\
\hline \multicolumn{9}{|l|}{ BMI } \\
\hline Low & $\begin{array}{r}0.278 \\
\pm 0.845\end{array}$ & $\begin{array}{r}0.270 \\
\pm 0.849\end{array}$ & $\begin{array}{r}0.218 \\
\pm 0.890\end{array}$ & $\begin{array}{r}0.417 \\
\pm 0.700\end{array}$ & $\begin{array}{r}0.253 \\
\pm 0.870\end{array}$ & $\begin{array}{l}F=5.57 \\
P=.003\end{array}$ & $\begin{array}{l}F=12.5 \\
P<.001\end{array}$ & \\
\hline Mid & $\begin{array}{r}0.218 \\
\pm 0.889\end{array}$ & $\begin{array}{r}0.182 \\
\pm 0.880\end{array}$ & $\begin{array}{r}0.220 \\
\pm 0.873\end{array}$ & $\begin{array}{r}0.298 \\
\pm 0.758\end{array}$ & $\begin{array}{r}0.200 \\
\pm 0.879\end{array}$ & $\eta_{p}^{2}=0.001$ & $\eta_{p}^{2}=0.001$ & \\
\hline High & $\begin{array}{r}0.222 \\
\pm 0.865\end{array}$ & $\begin{array}{r}0.188 \\
\pm 0.891\end{array}$ & $\begin{array}{r}0.229 \\
\pm 0.882\end{array}$ & $\begin{array}{r}0.228 \\
\pm 0.821\end{array}$ & $\begin{array}{r}0.209 \\
\pm 0.891\end{array}$ & & & \\
\hline All family incomes & $\begin{array}{r}0.222 \\
\pm 0.881\end{array}$ & $\begin{array}{r}0.188 \\
\pm 0.882\end{array}$ & $\begin{array}{r}0.223 \\
\pm 0.884\end{array}$ & $\begin{array}{r}0.251 \\
\pm 0.800\end{array}$ & $\begin{array}{r}0.206 \\
\pm 0.881\end{array}$ & $\begin{array}{l}F=0.57 \\
P=.633\end{array}$ & $\begin{array}{l}F=0.105 \\
P=.349\end{array}$ & $\begin{array}{l}F=0.81 \\
P=.565\end{array}$ \\
\hline
\end{tabular}

Values are unadjusted means $( \pm \mathrm{SD})$ for age- and sex-normalised $\mathrm{z}$ scores based on the World Health Organization/Centers for Disease Control and Prevention reference data. F values and $\eta_{p}^{2}{ }^{2}$ calculated from ANCOVA, adjusted for sex.

*Significantly different from very low SES and low SES groups at $P<.001$.

†Significantly different from very low SES (Bonferroni post hoc comparison) at $P<.01$. 
Table III. Differences in muscular and cardiorespiratory fitness in 14- to 16-year-old adolescents from Bogota, Colombia, according to area-level SES and family income

\begin{tabular}{|c|c|c|c|c|c|c|c|c|}
\hline Family incomes & Very low SES & Low SES & Mid SES & High SES & All SES & SES & Family income & Interaction \\
\hline \multicolumn{9}{|l|}{ Standing long jump } \\
\hline Low & $\begin{array}{l}-0.394 \\
\pm 0.931\end{array}$ & $\begin{array}{l}-0.323 \\
\pm 0.933\end{array}$ & $\begin{array}{l}-0.160 \\
\pm 0.931\end{array}$ & $\begin{array}{l}-0.049^{\dagger} \\
\pm 0.831\end{array}$ & $\begin{array}{c}-0.274 \\
0.85\end{array}$ & $\begin{array}{l}F=68.5 \\
P<.001\end{array}$ & $\begin{array}{l}F=2.40 \\
P=.094\end{array}$ & - \\
\hline \multirow[t]{2}{*}{ Mid } & -0.367 & -0.311 & -0.237 & $-0.193^{\dagger}$ & -0.293 & $\eta_{p}^{2}=0.012$ & & \\
\hline & \pm 0.930 & \pm 0.931 & \pm 0.836 & \pm 0.902 & 0.828 & & & \\
\hline \multirow[t]{2}{*}{ High } & -0.340 & -0.298 & -0.228 & $-0.079^{\dagger}$ & -0.266 & & & \\
\hline & \pm 0.899 & \pm 0.901 & \pm 0.900 & \pm 0.959 & 0.848 & & & \\
\hline All family income & $\begin{array}{l}-0.360 \\
\pm 0.838\end{array}$ & $\begin{array}{l}-0.307 \\
\pm 0.824\end{array}$ & $\begin{array}{l}-0.230 \\
\pm 0.843\end{array}$ & $\begin{array}{l}-0.114^{\star} \\
\pm 0.884\end{array}$ & $\begin{array}{r}-0.283 \\
0.835\end{array}$ & $\begin{array}{l}F=27.5 \\
P<.001 \\
\boldsymbol{\eta}_{p}^{2}=\mathbf{0 . 0 0 2}\end{array}$ & $\begin{array}{l}F=1.26 \\
P=.285\end{array}$ & $\begin{array}{l}F=1.46 \\
P=.193\end{array}$ \\
\hline \multicolumn{9}{|l|}{ Handgrip } \\
\hline Low & $\begin{array}{l}-0.345 \\
\pm 0.925\end{array}$ & $\begin{array}{l}-0.364 \\
\pm 0.920\end{array}$ & $\begin{array}{l}-0.395 \\
\pm 0.949\end{array}$ & $\begin{array}{l}-0.622 \\
\pm 0.925\end{array}$ & $\begin{array}{r}-0.368 \\
0.947\end{array}$ & $\begin{array}{l}F=8.2 \\
P<.001\end{array}$ & $\begin{array}{l}F=2.77 \\
P=.063\end{array}$ & - \\
\hline Mid & $\begin{array}{l}-0.411 \\
\pm 0.934\end{array}$ & $\begin{array}{l}-0.416 \\
\pm 0.925\end{array}$ & $\begin{array}{l}-0.398 \\
\pm 0.912\end{array}$ & $\begin{array}{l}-0.544 \\
\pm 0.826\end{array}$ & $\begin{array}{r}-0.411 \\
0.921\end{array}$ & $\eta_{p}^{2}=0.001$ & & \\
\hline High & $\begin{array}{r}-0.403 \\
0.894\end{array}$ & $\begin{array}{l}-0.402 \\
\pm 0.899\end{array}$ & $\begin{array}{l}-0.398 \\
\pm 0.903\end{array}$ & $\begin{array}{l}-0.529 \\
\pm 0.951\end{array}$ & $\begin{array}{r}-0.406 \\
0.903\end{array}$ & & & \\
\hline All family income & $\begin{array}{l}-0.368 \\
\pm 0.947\end{array}$ & $\begin{array}{l}-0.411 \\
\pm 0.921\end{array}$ & $\begin{array}{l}-0.406 \\
\pm 0.902\end{array}$ & $\begin{array}{l}-0.407 \\
\pm 0.916\end{array}$ & $\begin{array}{r}-0.407 \\
0.916\end{array}$ & $\begin{array}{l}F=0.86 \\
P=.461\end{array}$ & $\begin{array}{l}F=0.92 \\
P=.393\end{array}$ & $\begin{array}{l}F=0.22 \\
P=.969\end{array}$ \\
\hline \multicolumn{9}{|l|}{ 20-m shuttle-run } \\
\hline Low & $\begin{array}{l}-0.531 \\
\pm 0.646\end{array}$ & $\begin{array}{l}-0.622 \\
\pm 0.652\end{array}$ & $\begin{array}{l}-0.552 \\
\pm 0.670\end{array}$ & $\begin{array}{l}-0.318^{\star} \\
\pm 0.554\end{array}$ & $\begin{array}{r}-0.553 \\
0.681\end{array}$ & $\begin{array}{l}F=20.5 \\
P<.001\end{array}$ & $\begin{array}{l}F=0.33 \\
P=.716\end{array}$ & \\
\hline Mid & $\begin{array}{l}-0.522 \\
\pm 0.703\end{array}$ & $\begin{array}{l}-0.553 \\
\pm 0.680\end{array}$ & $\begin{array}{l}-0.503 \\
\pm 0.676\end{array}$ & $\begin{array}{l}-0.575 \\
\pm 0.666\end{array}$ & $\begin{array}{r}-0.537 \\
0.681\end{array}$ & $\eta_{p}^{2}=0.002$ & & \\
\hline High & $\begin{array}{l}-0.508 \\
\pm 0.717\end{array}$ & $\begin{array}{l}-0.579 \\
\pm 0.689\end{array}$ & $\begin{array}{l}-0.495 \\
\pm 0.684\end{array}$ & $\begin{array}{l}-0.583 \\
\pm 0.735\end{array}$ & $\begin{array}{r}-0.534 \\
0.692\end{array}$ & & & \\
\hline All family income & $\begin{array}{l}-0.518 \\
\pm 0.704\end{array}$ & $\begin{array}{l}-0.564^{\dagger} \\
\pm 0.682\end{array}$ & $\begin{array}{l}-0.502 \\
\pm 0.679\end{array}$ & $\begin{array}{l}-0.578^{\dagger} \\
\pm 0.713\end{array}$ & $\begin{array}{r}-0.537 \\
0.685\end{array}$ & $\begin{array}{l}F=8.3 \\
P<.001 \\
\boldsymbol{\eta}_{\boldsymbol{p}}^{2}=\mathbf{0 . 0 0 1}\end{array}$ & $\begin{array}{l}F=0.93 \\
P=.911\end{array}$ & $\begin{array}{l}F=1.17 \\
P=.380\end{array}$ \\
\hline
\end{tabular}

Values are unadjusted means (SD) for age- and sex-normalized $z$ scores. F values and $\eta_{p}{ }^{2}$ calculated from ANCOVA adjusted for sex. Sex appears as a significant covariate for standing long jump $\left(F=975, P<.0001 \eta_{p}^{2}=.018\right)$, handgrip $\left(F=25853, P<.0001 \eta_{p}^{2}=.331\right)$, and 20-m shuttle-run test $\left(F=3.95, P=.001, \eta_{p}^{2}=.031\right)$.

${ }^{\star}$ Significantly different from very low SES and low SES groups at $P<.001$.

†Significantly different from very low SES (Bonferroni post hoc comparison) at $P<.01$. 